\title{
The Influence of Structured and
}

\section{Unstructured After-School Activities}

on Academic Performance of Junior

High School Students in Cape Coast

Metropolis in the Central

Region of Ghana

\author{
David Turkson'1, Francis Britwum¹, Abraham Yeboah' \\ ${ }^{1}$ Department of Education and Psychology, University of Cape Coast, Cape Coast, Ghana \\ ${ }^{2}$ Department of Pedagogy, Akrokerri College of Education, Akrokerri, Ghana \\ Email: turksondavid09@yahoo.com, francisbritwum@gmail.com, abrahamyeboah290@gmail.com
}

How to cite this paper: Turkson, D., Britwum, F., \& Yeboah, A. (2021). The Influence of Structured and Unstructured After-School Activities on Academic Performance of Junior High School Students in Cape Coast Metropolis in the Central Region of Ghana. Creative Education, 12, 356-368.

https://doi.org/10.4236/ce.2021.122025

Received: December 14, 2020

Accepted: February 7, 2021

Published: February 10, 2021

Copyright $\odot 2021$ by author(s) and Scientific Research Publishing Inc. This work is licensed under the Creative Commons Attribution International License (CC BY 4.0).

http://creativecommons.org/licenses/by/4.0/

\begin{abstract}
Despite the fact that adolescents' waking hours are flexible, little is known about the links of adolescents' choices of leisure time activities for academic, psychological and behavioural functioning. Participation in activities can provide opportunities to develop specific skills and to interact with nurturing and caring adults as well as a sense of belonging with particular peer groups and recognition from others. Time use and monitor studies have provided rich descriptive pictures of adolescents' daily lives including what teens do, who they are with and their affective states across their out-of-school experiences. The study therefore examined the influence of structured and unstructured activities on academic performance of Junior High School students in Cape Coast Metropolis in the Central Region of Ghana. A descriptive survey design was adopted using a sample of 364 students selected from six public junior high schools in Cape Coast. A questionnaire was used to gather the data. The Cronbach's alpha co-efficient for the reliability of the instrument was 0.76 . Simple linear regression was used as statistical tools to analyse the data collected. The findings of the study were that both structured and unstructured activities respectively do influence students' academic performance. It was recommended that stakeholders such as parents, guardians, and teachers must be aware of the kind of after-school activity their wards/students engage in so as to help them make better choices due to the influence that their choices make on their academic performance.
\end{abstract}




\section{Keywords}

Structured Activities, Unstructured Activities, After-School Activities and Extra-Curricular Activities

\section{Introduction}

The activities adolescents participate in after-school may be structured activities or unstructured activities. According to Pittman, Tolman and Yohalem (2005), structured activity is planned, directed, designed for child's developmental level and it is an organized activity with an instructional purpose. According to Marsh (2002), participation in extra-curricular activities (ECA) is only one of the many choices adolescents make regarding their discretionary time. Among the teens that participate in extra-curricular activities, some also participate in structured activities within the community such as sports teams, youth groups or hobbies. Others work at paid jobs or spend a greater amount of their time helping families by caring for younger siblings.

On the other hand unstructured activities constitute a large component of adolescents' lives and unstructured activities, which are self-directed and occur mostly when children explore their environment. Adolescents like to spend their free time with peers, either face-to-face or via the telephone, discussing topics of interest such as behaviours of other group members, fashion, music and television programmes (Coleman \& Hendry, 2000). The interaction underpinning many leisure activities serves as an important avenue for the development of friendship networks and is a beneficial cue to engaging in activities (Tergerson \& King, 2002). Through friendships, adolescents develop social competence, receive security and support, and feel happy (Coleman \& Hendry, 2000).

Adolescents mostly participate in out-of-school activities which either improve their development or hamper their development. Here, when adolescents engage in out-of-school activities like attending to assignment given in school, reading of novel or the dailies, it will contribute to the academic performance of the adolescent. However, it is perceived that situations where adolescents become addicted to watching cartoons on the television set, playing football and many other equally "unprofitable" activities, will hamper the academic performance of the adolescent at school.

Hendry (2003) hypothesized that if individuals do not meet their social and individual developmental requirements due to either external (accessibility and influence of others) or internal (self-motivation, interest) constraints, then progress through adolescence may be unsatisfactory and psychologically unhealthy. It is suggested that the type of activities in which adolescents participate in outside school plays an important role in helping to meet these requirements. These activities can be structured or unstructured activities. For instance, studies of younger children by University of Wisconsin Madison psychologist Deborah 
Lowe Vandell as cited in DeAngleis (2001), found out that structured after-school activities such as music and art help develop skills such as concentration that can help them perform better in school.

Involvement in structured out-of-school activities may provide adolescents with a range of development enhancing opportunities that are not necessarily available in the more constrained domain of education. Conversely, some types of unstructured activities may predict adolescent adjustment difficulties and negative outcomes or may even enhance their physiological, psychological or social gains (i.e. general well-being of the adolescent).

The holistic development of adolescents is mostly centered on the activities (structured activities and unstructured activities) that they partake in outside the normal school hours. Adolescent students in the Cape Coast Metropolis do engage in varied forms of after-school activities such as engaging in sporting activities, reading books, engaging in personal extra-classes and group studies. The rest include watching television, trading, attending social gatherings, engaging in house chores, spending time to chat with friends (e.g. via phones), among others. It has become expedient therefore, to investigate how their engagement in these activities (i.e. both structured and unstructured activities) influences their academic performance.

\subsection{Statement of the Problem}

Over the past few years, concerns have been raised by stakeholders predominantly teachers, that the performance, under-performance or non-performance of students is due to the kind of activities they engage in after-school. Students are found in partaking in varied forms of activities after-school such as performing chores at home, hanging out with friends, watching television, reading for pleasure, engaging in paid work, joining sports teams and clubs among others. These activities could either cushion or hinder the academic development of adolescent (Goerge, 2007).

According to Barber, Eccles and Stone (2001), participation in an activity like sports is associated with higher academic performance during high school and greater likelihood of attending college, and higher mental health is also linked to increased alcohol use during the high school years. This latter idea gives the impression that out-of-school activities could have an adverse effect on the academic performance of the adolescent.

Much of the previous research has examined a single activity domain and the corresponding links to academic and social performance. A number of studies (e.g., Eccles \& Barber, 2003; Marsh, 2002; Bartko \& Eccles, 1998; Landers \& Landers, 2008; McNeal, 2005; Bartko, Eccles, \& Barber, 2000), for example, have reported that participation in extracurricular activities is related to better academic performance. Whether or not to participate in extracurricular activities, however, is only one of the many choices adolescents' make regarding their discretionary time.

Of the various researches reviewed, studies conducted were predominantly on 
extracurricular activities on academic performance. Adolescents in the Cape Coast metropolis participate in varied forms of after-school activities which may not be necessarily extracurricular activities such as sports, extra-classes, group studies, club meetings, religious meetings, social gatherings, trading, reading, chatting with friends among others.

The focus of this study is therefore to look at student's after-school activity choices and their influence on academic performance of Junior High School (J.H.S) students in the Cape Coast Metropolis. A broad array of activity indicators are included in order to capture the total picture of students' behavioral choices, including school-related extracurricular activities, structured activities, adult-led activities, unstructured leisure activities and paid employment.

\subsection{Research Hypotheses}

1) $\mathrm{H}_{0}$ : There is no statistically significant influence of structured activities on students' academic performance.

$\mathrm{H}_{1}$ : There is a statistically significant influence of structured activities on students' academic performance.

2) $H_{0}$ : There is no statistically significant influence of unstructured activities on students' academic performance.

$\mathrm{H}_{1}$ : There is a statistically significant influence of unstructured activities on students' academic performance.

\section{Literature Review}

\section{Developmental Framework}

The dominant theoretical framework in the general education literature is the developmental framework by Broh (2002), which theorized that ECA participation has a positive effect on academic performance indirectly as a result of the non-academic and social benefits associated with ECA participation.

Broh (2002) pointed out that there are three ways which ECA participation indirectly boosts students' academic performance. First, ECA participation helps students develop life skills and characteristics such as a strong work ethic, self-esteem, perseverance, locus of control, which are consistent with positive academic outcomes. Second, participating in ECA increases students' social status and accords them membership into the leading-crowd of academically oriented peer group, thereby facilitating higher academic performance. Third, ECA participation provides students with greater interaction with fellow students in the school, thereby building social ties and developing social capital. This social capital then acts as a form of social control that encourages students to follow school norms and thus attain academic success. ECA participation facilitates students to achieve better academic performance through acquiring life skills and attitudes (Holland \& Andre, 2007; Larson, 2006; Lewis, 2004; Mahoney, Cairns, \& Farmer, 2003; Marsh, 2002).

Holland and Andre suggested that ECA participation helps students to ac- 
quire organizational, planning and time-management skills. They also suggested that ECA participation helps students to develop attitudes such as discipline and motivation; and to receive social rewards that influence personality characteristics (Holland \& Andre, 2007). Marsh (2002) and Valentine, Cooper, \& Bettencourt (2002) found that ECA participation enhances students' self-concept, which in turn mediates positive effects on other academic outcomes. ECA participation also promotes personal initiatives such as setting personal goals, evaluating what is needed to attain goals, and then actively acquiring the abilities and resources to achieve goals (Larson, 2006). Over time, the benefits of consistent ECA participation could generalize beyond the ECA setting towards academic pursuits such as in academic goal setting (Mahoney et al., 2003). Mahoney (2001) conducted a longitudinal study and found that consistent ECA participation was associated with high interpersonal competence, educational status, and educational aspirations.

Lewis (2004) proposed the application of resilience theory to examine the positive impacts of ECA participation. Resilience is one's ability to respond positively to stress, adversity, and obstacles, learned as a result of exposure to challenging situations (Rutter, 2007). Lewis argued that ECA participation acts as an agent of resilience by providing students with new environments for self-discovery, opening up opportunities for achievement, and allowing them to assume meaningful roles in their school communities. Lewis also argued that ECA participation enhances students' self-esteem and self-efficacy and motivates them to work towards academic goals and social relations. This results in a stronger sense of school belonging, which can motivate students to work towards academic goals (Lewis, 2004). The achievement-oriented nature of ECA, especially sports activities, is an ideal context for building students' character (Fejgin, 2004). Fejgin found that students who participated in competitive sport activities developed a greater internal locus of control. By making experiences of both success and failure highly visible to participants and their peers, students realize that achievements depend on individual effort. This link between performance and achievement in competitive sports might help students to establish a greater internal locus of control and achieve better academic performance (Fejgin, 2004).

Hansen, Larson, and Dworkin (2003) examined the developmental benefits of ECA participation and suggested that ECA participation provides students with six basic domains of learning experiences that may lead to positive academic outcomes. ECA participation assists the personal development of students by 1) facilitating identity development through trying out new experiences; 2) providing a context for developing personal initiative; 3) developing basic emotional, cognition, and physical skills; 4) building social connections to others through developing teamwork and social skills; 5) promoting interpersonal relationships; and 6) extending social networks with both peers and adults which are a source of social capital (Hansen et al. 2003). ECA participation may be a key factor in increasing students' sense of school belonging. Students who have a greater sense of school belonging were more likely to be more interested in school, more 
motivated, experienced less anxiety and had improved academic performance (Fredricks \& Eccles, 2010).

Anderman (2002) found that students who felt a greater sense of school belonging obtained a higher grade point average, were more optimistic, and had fewer problems at school. Marsh (2002) argued that through ECA involvement, students experience a sense of meaning and purpose connected to the educational process, which increases their sense of commitment to the school. This results in shaping students' values and attitudes to become more consistent with the academic-oriented school values and to the academic process in general as reflected through lower school dropout rates and school attendance (Marsh, 2002; Mahoney \& Cairns, 2007).

Conclusions from these studies suggest that quality after-school activities can have positive impact on students' academic performance. Involvement in extra-curricular activities is consistently and positively correlated with good school attendance and good attendance is often correlated with higher grade point average (Olson, 2008). Smith (2008) posited that participation in extra-curricular activities provide students with unique development opportunities that positively impact on the students' self-concept. This may lead to higher academic expectations therefore better academic outcomes for students.

However, Reeves (2008) determined that parents and teachers might fear students may lose their focus on academics when they become too busy with after-school activities. This study, hitherto, seeks to determine the applicability of the framework on the study.

\section{Conceptual Framework}

Students participate in varied forms of after-school structured activities ranging from: engaging in games such as football clubs, athletic teams, drama clubs, group studies, reading books and writing of poems; to unstructured activities such as "hanging out" with friends, house chores, watching movies, listening to music as well as engaging in social gathering e.g. beach parties and street jams. As students, the frequencies with which they participate in these activities have a bearing on their academic performance.

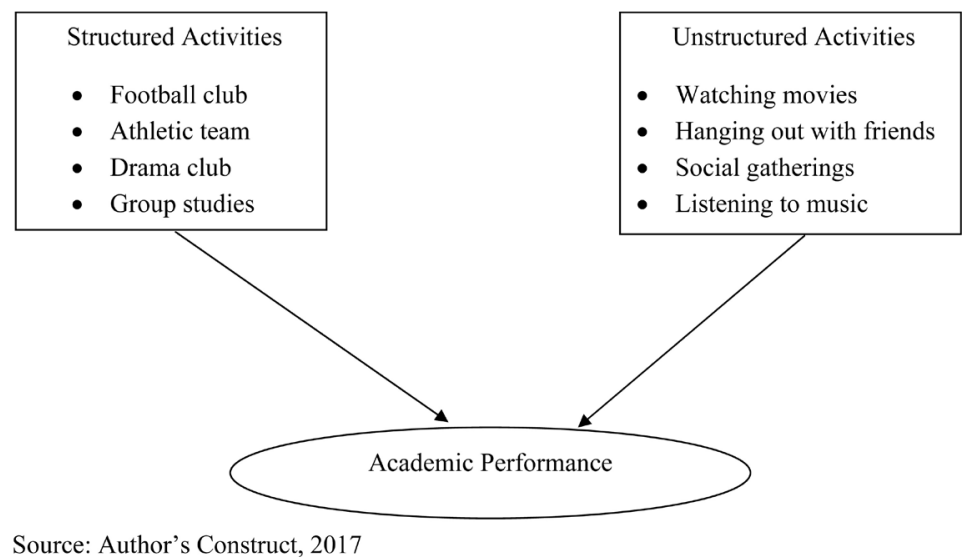




\section{Methodology}

\subsection{Research Design}

The study employed a descriptive cross-sectional survey in the study. Therefore, the data generated was analyzed quantitatively. According to Gay (1992), the descriptive survey is an attempt to collect data from members of the population in order to determine the current status of that population with respect to one or more variables. Burns and Grove (2003) define a research design as "a blueprint for conducting a study with maximum control over factors that may interfere with the validity of the findings". Research design is a plan that describes how, when and where data are to be collected and analysed. Polit, Beck, \& Hungler (2001) define a research design as "the researcher's overall plan for answering the research question or testing the research hypothesis". The descriptive research design allows for generalization of findings from sample to population. In descriptive survey a whole lot of information can be collated and gathered on a large and hefty sample within a short time frame with the survey.

\subsection{Population}

In this study, the target population was students from all Junior High Schools (J.H.S) in the Cape Coast Metropolis which consisted of 7487 students. For the purpose of the study, the accessible population constituted all J.H.S 3 students from public Junior High Schools in the Cape Coast Metropolis.

\subsection{Sample Size and Sampling Procedure}

In all a total of 364 respondents from six schools were used. According to Krejcie and Morgan (1970), the sample size of 364 respondents has an estimated population of 7000 .

The stratified random sampling technique was used in selecting the circuits since the Cape Coast Metropolis is divided into six blocks (circuits). There were sixty-one public Junior High Schools in the Cape Coast Metropolis; with each circuit having between nine (9) and eleven (11) schools. Therefore for equal representation of schools for the study, the researcher simple randomly selected a school from each of the six (6) circuits in the Metropolis. In respect of the sample for the study, all J.H.S 3 students in the selected public schools were used for the study.

\subsection{Data Collection Instrument}

The instrument used in the study was a Structured and Unstructured After-school Activities questionnaire. A four point Likert-scale was designed to examine the influence of after-school activities (structured and unstructured) on students' academic performance. There were 7 items each on both the research hypotheses 1 and 2 which focused on the influence of structured and unstructured activities on academic performance respectively. The four point $\mathrm{Li}$ kert-scale provides a range of responses to a given statement; that is (1) Strongly 
Disagree (2) Disagree (3) Agree (4) Strongly Agree.

\subsection{Reliability of Instrument}

The Cronbach's Alpha method of determining reliability co-efficient was used to determine the internal consistency of the instrument. Reliability co-efficient for items on research hypothesis 1 and 2 (i.e. structured and unstructured after-school activities) were 0.75 and 0.76 respectively. The overall Cronbach's co-efficient alpha for the study was 0.755. According to Roland and Isdoe (2001), this score is regarded as significant for a research purpose.

\section{Data Processing and Analysis}

The responses to the questionnaires were edited, coded and scored. Frequencies and percentages and simple linear regression were used for the analysis. In measuring academic performance, data on test scores retrieved from the respective schools were converted to $\mathrm{z}$-scores to reduce errors.

\section{Results}

Table 1. Distribution of respondents by gender.

\begin{tabular}{ccc}
\hline Gender & Frequency & Percentage \\
\hline Male & 140 & 38.5 \\
Female & 224 & 61.5 \\
Total & 364 & 100.0 \\
\hline
\end{tabular}

Source: Field Data (Turkson, Britwum, \& Yeboah, 2017).

1) Inferring from Table 1, out of the 364 respondents who were involved in the study, 140 were males representing $38.5 \%$ whiles 224 were females representing $61.5 \%$. Thus, the majority of the respondents were female.

Table 2. Distribution of respondents by age.

\begin{tabular}{ccc}
\hline Age & Frequency & Percentage \\
\hline $12-15$ years & 242 & 66.5 \\
$16-19$ years & 120 & 33.0 \\
$20-23$ years & 2 & .5 \\
Total & 364 & 100.0 \\
\hline
\end{tabular}

Source: Field Data (Turkson, Britwum, \& Yeboah, 2017).

2) Table 2 shows that 242 out of the 364 respondents were in the age range of 12 and 15 years, representing $66.5 \%$ whiles 120 were within the ages of 16 and 19 years, representing 33.0\%. However, only 2 out of the 364 respondents were within the ages of 20 and 23 years, representing $0.5 \%$. Nonetheless, the majority of the students were within the ages of 12 and 15. 


\subsection{Research Hypothesis One}

$\mathrm{H}_{0}$ : There is no statistically significant influence of structured activities on students' academic performance.

$\mathrm{H}_{1}$ : There is a statistically significant influence of structured activities on students' academic performance.

Research hypothesis one sought to find out from respondents whether their engagement in structured activities have bearing on their academic performance. Simple linear regression analysis was conducted as presented in Table 3.

From Table 3, the results indicated that structured activities have influence on academic performance of students $(\mathrm{r}=0.141, P<0.05)$. Also, structured activities account for $2.0 \%$ of the variation in the academic performance of students.

\subsection{Research Hypothesis Two}

$\mathrm{H}_{0}$ : There is no statistically significant influence of unstructured activities on students' academic performance.

$\mathrm{H}_{1}$ : There is a statistically significant influence of unstructured activities on students' academic performance.

Research hypothesis two sought to find out from respondents whether their engagement in unstructured activities have bearing on their academic performance. Simple linear regression analysis was conducted as presented in Table 4. From Table 4, the results indicated that unstructured activities have influence on academic performance of students $(\mathrm{r}=0.104, P<0.05)$. Also, unstructured activities account for $1.1 \%$ of the variation in the academic performance of students.

Table 3. Regression analysis of influence of structured activities on academic performance of students.

\begin{tabular}{|c|c|c|c|c|c|c|}
\hline \multirow{2}{*}{ Model } & \multicolumn{2}{|c|}{ Unstandardised Coefficients } & \multirow{2}{*}{$\begin{array}{c}\begin{array}{c}\text { Standardised } \\
\text { Coefficients }\end{array} \\
\text { Beta }\end{array}$} & \multirow{2}{*}{$\begin{array}{l}\text { R square } \\
\text { change }\end{array}$} & \multirow{2}{*}{$\mathrm{t}$} & \multirow{2}{*}{ Sig. } \\
\hline & B & Std. Error & & & & \\
\hline (Constant) & 219.573 & 10.916 & & & 20.114 & 0.000 \\
\hline Structured & -0.981 & 0.363 & 0.141 & 0.020 & -2.702 & 0.007 \\
\hline
\end{tabular}

Dependent Variable: Academic scores.

Table 4. Regression analysis of influence of unstructured activities on academic performance of students.

\begin{tabular}{ccccccc}
\hline \multirow{2}{*}{ Model } & \multicolumn{2}{c}{ Unstandardised Coefficients } & $\begin{array}{c}\text { Standardised } \\
\text { Coefficients }\end{array}$ & $\begin{array}{c}\text { R square } \\
\text { change }\end{array}$ & t & Sig. \\
\cline { 2 - 5 } (Constant) & 214.030 & 11.966 & Beta & & & \\
\hline Unstructured & -0.662 & 0.333 & 0.104 & 0.011 & -1.985 & 0.000 \\
\hline
\end{tabular}

Dependent Variable: Academic scores. 


\section{Discussion}

On research hypothesis one, the findings of the study were in line with earlier studies by Gilman (2001), Bartko and Eccles (1998), Mahoney (2001) and Mahoney and Cairns (2007) that participation in structured extracurricular activities are associated with increased school satisfaction, high academic performance and lower school "drop-out" rates. Structured activities may facilitate academic achievement and school satisfaction by enhancing adolescents' identification with their school and school values, increasing their investment in education and promoting better academic attitudes and habits. However, this result contradicts that of zero-sum framework which theorised that structured extracurricular activities (ECA) participation has a negative effect on academic performance because students devote more time for their ECA activities at the expense of their academic studies (Coleman, 2002). Porter (2001) argued that heavy structured extracurricular activities participation interferes with academic work, resulting in students spending less time on their homework. ECA participation requires time commitments from students, and these time requirements are in direct competition with time that otherwise could have been spent on academic pursuits (Camp, 2000; Coleman, 2002; Joekel, 1985; Marsh, 2002; Marsh \& Kleitman, 2002; Porter, 2001).

On research hypothesis two, the study is in line with the threshold framework, which theorised that unstructured extracurricular activities (ECA) participation has a positive effect on academic performance up to a certain point beyond which participation leads to negative academic outcomes (Cooper, Valentine, Nye, \& Lindsay, 1999; Fredricks, 2012; Fredricks \& Eccles, 2010; Knifsend \& Graham, 2012; Randall \& Bohnert, 2012). The threshold framework posits that the association between ECA participation and academic outcomes resembles an inverted U-shaped function, in which academic outcomes increase at low and moderate levels of ECA participation, level off, then decline at the highest participation levels (Fredricks, 2012; Marsh, 2002). The threshold framework attributes the point of diminishing academic benefits to students' excessive time commitment which leaves students too little time for academic pursuits, similar to the zero-sum framework (Marsh, 2002).

\section{Conclusion}

The main findings from the data analysis were that: 1) there was a significant influence of structured activities on students' academic performance and 2) there was a significant influence of unstructured activities on students' academic performance.

The study therefore revealed that both structured and unstructured activities respectively do influence students' academic performance. It could hence, be concluded that after-school activities have effect on students' academic performance.

The researcher, therefore, recommends that the Ghana Education Service 
(G.E.S.) as a major stakeholder of education in the country should include programmes and activities that would ensure that policies on adolescents' after-school activities are rightly implemented and monitored. Adolescents could also be talked to about the various activities available and how they would make right and better choices to cushion their academic performance and their total being as a whole. And also, parents should encourage their wards to engage in good unstructured activities. This would help students to learn new things thereby cushioning their academic performance in school.

\section{Conflicts of Interest}

The authors declare no conflicts of interest regarding the publication of this paper.

\section{References}

Anderman, E. M. (2002). School Effects on Psychological Outcomes during Adolescence. Journal of Educational Psychology, 94, 795-809. https://doi.apa.org/doi/10.1037/0022-0663.94.4.795

Barber, B. L., Eccles, J. S., \& Stone, M. R. (2001). Whatever Happened to the Jock, the Brain, and the Princess? Youth Pathways Linked to Adolescent Activity Involvement and Social Identity. Journal of Adolescent Research, 16, 429-455.

https://doi.org/10.1177\%2F0743558401165002

Bartko, W. T., \& Eccles, J. (1998). Adolescent Extracurricular Activity Participation. Links to Parents, Families, Peers and School. Biennial Meeting of International Society for the Study of Behavioural Development, Berne, Switzerland.

Bartko, W. T., Eccles, J., \& Barber, B. (2000). Predicting Adolescent Participation in Constructive Activities from a Motivational Perspective. Winchester: British Psychological Society.

Broh, B. A. (2002). Linking Extracurricular Programming to Academic Achievement: Who Benefits and Why? Sociology of Education, 75, 69-95. https://doi.org/10.2307/3090254

Burns, N. H., \& Grove, J. W. (2003). Experimental Assessment of Factors Affecting Transfer Length. Structural Journal, 100, 740-748. https://doi.org/10.14359/12840

Camp, W. G. (2000). Participation in Student Activities and Achievement: A Covariance Structural Analysis. The Journal of Educational Research, 83, 272-278. https://doi.org/10.1080/00220671.1990.10885969

Coleman, J. C. (2002). Current Views of the Adolescent Process. In J. C. Coleman, \& L. B. Hendry (Eds.), The Nature of Adolescence (3rd ed.). New York, NY: Routledge.

Coleman, J. C., \& Hendry, L. B. (2000). The Nature of Adolescence (3rd ed.). New York, NY: Routledge.

Cooper, H., Valentine, J. C., Nye, B., \& Lindsay, J. J. (1999). Relationships between Five After-School Activities and Academic Achievement. Journal of Educational Psychology, 91, 369-378. https://doi.apa.org/doi/10.1037/0022-0663.91.2.369

DeAngleis, A. (2001). The Experience of Leisure in Adolescence. Journal of Leisure Research, 18, 165-176.

Eccles, J. S., \& Barber, B. L. (2003). Student Council, Volunteering, Basketball, or Marching Band. What Kind of Extracurricular Involvement Matters? Journal of Youth and 
Adolescence, 32, 233-241.

Fejgin, N. (2004). Participation in High School Competitive Sports: Subversion of School Mission or Contribution to Academic Goals? Sociology of Sport Journal, 11, 211-230. https://doi.org/10.1123/ssj.11.3.211

Fredricks, J. A. (2012). Extracurricular Participation and Academic Outcomes: Testing the Over-Scheduling Hypothesis. Journal of Youth and Adolescence, 41, 295-306. https://doi.org/10.1007/s10964-011-9704-0

Fredricks, J. A., \& Eccles, J. S. (2010). Breadth of Extracurricular Participation and Adolescent Adjustment among African-American and European American Youth. Journal of Research on Adolescence, 20, 307-333. https://doi.org/10.1111/j.1532-7795.2009.00627.x

Gay, L. R. (1992). Educational Research: Competencies for Analysis and Application (4th ed.). New York, NY: Merrill/Macmillan.

Gilman, R. (2001). The Relationship between Life Satisfaction, Social Interest, and Frequency of Extracurricular Activities among Adolescent Students. Journal of Youth and Adolescence, 30, 749-768. https://doi.org/10.1023/A:1012285729701

Goerge, R. M. (2007). After-School Programs and Academic Impact: A Study of Chicago's After-School Matters. Chicago, IL: University of Chicago Press.

Hansen, D. M., Larson, R. W., \& Dworkin, J. B. (2003). What Adolescents Learn in Organized Youth Activities: A Survey of Self-Reported Developmental Experiences. Journal of Research on Adolescence, 13, 25-55. https://doi.org/10.1111/1532-7795.1301006

Hendry, L. B. (2003). Growing up and Going out: Adolescents and Leisure. Aberdeen: Aberdeen University Press.

Holland, A., \& Andre, T. (2007). Participation in Extracurricular Activities in Secondary School: What Is Known, What Needs to Be Known? Review of Educational Research, 57, 437-466. https://doi.org/10.3102\%2F00346543057004437

Joekel, R. G. (1985). Student Activities and Academic Eligibility Requirements. NASSP Bulletin, 69, 3-9. https://doi.org/10.1177\%2F019263658506948302

Knifsend, C. A., \& Graham, S. (2012). Too Much of a Good Thing? How Breadth of Extracurricular Participation Relates to School-Related Affect and Academic Outcomes during Adolescence. Journal of Youth and Adolescence, 41, 370-389. https://doi.org/10.1007/s10964-011-9737-4

Krejcie, R. V., \& Morgan, D. W. (1970). Determining Sample Size for Research Activities. Educational and Psychological Measurement, 30, 607-610. https://doi.org/10.1177\%2F001316447003000308

Landers, D. \& Landers, D. (2008). Socialization via Interscholastic Athletics, Its Effect on Delinquency. Sociology of Education, 51, 299-301. https://doi.org/10.2307/2112368

Larson, R. W. (2006). Towards a Psychology of Positive Youth Development. American Psychologist, 55, 170-183. https://doi.apa.org/doi/10.1037/0003-066X.55.1.170

Lewis, C. P. (2004). The Relation between Extracurricular Activities with Academic and Social Competencies in School Age Children: A Meta-Analysis. PhD Dissertation, Austin, TX: Texas A \& M University.

Mahoney, J. L. (2001). Children Who Participated in School Extracurricular Activities Were Less Likely to Drop out or to Have Been Arrested. Evidence-Based Mental Health, 4, 29. http://dx.doi.org/10.1136/ebmh.4.1.29 
Mahoney, J. L., \& Cairns, R. B. (2007). Do Extracurricular Activities Protect against Early School Dropout? Developmental Psychology, 33, 241-253. https://doi.apa.org/doi/10.1037/0012-1649.33.2.241

Mahoney, J. L., Cairns, B. D., \& Farmer, T. W. (2003). Promoting Interpersonal Competence and Educational Success through Extracurricular Activity Participation. Journal of Educational Psychology, 95, 409-418.

https://doi.apa.org/doi/10.1037/0022-0663.95.2.409

Marsh, H. (2002). Extracurricular Activities: Beneficial Extension of the Traditional Curriculum of Subversion of Academic Goals? Journal of Educational Psychology, 84, 553-562. https://doi.apa.org/doi/10.1037/0022-0663.84.4.553

Marsh, H. W., \& Kleitman, S. (2002). Extracurricular School Activities: The Good, the Bad, and the Nonlinear. Harvard Educational Review, 72, 464-515. https://doi.org/10.17763/haer.72.4.051388703v7v7736

McNeal Jr., R. (2005). Extracurricular Activities and High School Drop-Outs. Sociology of Education, 68, 62-81. https://doi.org/10.2307/2112764

Olson, C. A. (2008). Can Music Education Help At-Risk Students? Study Finds Positive Testimony Substantial but Quantitative Research Lacking. Teaching Music, 16, 20.

Pittman, K., Tolman, J., \& Yohalem, N. (2005). Developing a Comprehensive Agenda for Out-of-School Hours: Lessons and Challenges across Cities. In J. L. Mahoney, R. Larson, \& J. S. Eccles (Eds.), Organized Activities as Contexts of Development: Extracurricular Activities, After-School and Community Programs (pp. 375-397). Mahwah, NJ: Lawrence Erlbaum Associates.

Polit, B., Beck, C. T., \& Hungler, R. (2001). Essentials of Nursing Research: Methods, Appraisal and Utilization. Philadelphia, PA: Lippincott Williams \& Wilkins.

Porter, A. C. (2001). Creating a System of School Process Indicators. Education and Policy Analysis, 13, 13-29. https://doi.org/10.3102\%2F01623737013001013

Randall, E. T., \& Bohnert, A. M. (2012). Understanding Threshold Effects of Organized Activity Involvement in Adolescents: Sex and Family Income as Moderators. Journal of Adolescence, 35, 107-118. https://doi.org/10.1016/j.adolescence.2011.05.004

Reeves, D. B. (2008). The Extracurricular Advantage. Education Leadership, 66, 86-87

Roland, E., \& Isdoe, T. (2001). Aggression and Bullying. Aggressive Behaviour, 27, 446-462. https://doi.org/10.1002/ab.1029

Rutter, M. (2007). Psychosocial Resilience and Protective Mechanisms. American Journal of Orthopsychiatry, 57, 316-331. https://doi.apa.org/doi/10.1111/j.1939-0025.1987.tb03541.x

Smith, S. L. (2008). Athletics \& Academics. New York, NY: Research Starters.

Tergerson, J. L., \& King, K. A. (2002). Do Perceived Cues, Benefits and Barriers to Physical Activity Differ between Male and Female Adolescents? The Journal of School Health, 72, 374-381. https://doi.org/10.1111/j.1746-1561.2002.tb03562.x

Turkson, D., Britwum, F., \& Yeboah, A. (2017). After-School Activities and Their Influence on Academic Performance of Junior High School Students in the Cape Coast Metropolis in the Central Region of Ghana. Unpublished Thesis, Cape Coast: University of Cape Coast.

Valentine, J. C., Cooper, H., \& Bettencourt, B. A. (2002). Out-of-School Activities and Academic Achievement: The Mediating Role of Self-Beliefs. Educational Psychologist, 37, 245-256. https://doi.org/10.1207/S15326985EP3704_4 